\title{
Lichtvoetige lijnen
}

Japanse schilderingen

uit de schenking

van Jan Piet Filedt Kok 
Cat. I Jongen met hak en zaailingen van rijst

Matsumura Goshun (1752-1811), Hangrolschildering, inkt en kleur op papier, signatuur: 'Gekkei sha' ('vervaardigd door Gekkei'), zegel: 'Goshun', Japan, eind ${ }^{\mathrm{e}}{ }^{\mathrm{e}}$ eeuw, Rijksmuseum, Amsterdam, inv.nr. AK-RAK-2015-2-4.

Schenking van de heer Filedt Kok, Amsterdam, 2015.

Op deze schets is een jongen met een hak over zijn schouder op het platteland onderweg met zaailingen van rijst. De ritmisch krullende kalligrafie (nog onvertaald) sluit aan bij de zwierige lijnen waarmee Goshun de figuur heeft geportretteerd. Hij signeerde met Gekkei, de artiestennaam die Goshun aannam in het begin van zijn carrière, tegen I777. In die periode werd hij gevormd door zijn leermeester en grote voorbeeld Yosa Buson (I7I6-I783), die ook vergelijkbare figuurstudies liet vergezellen door tekst. 


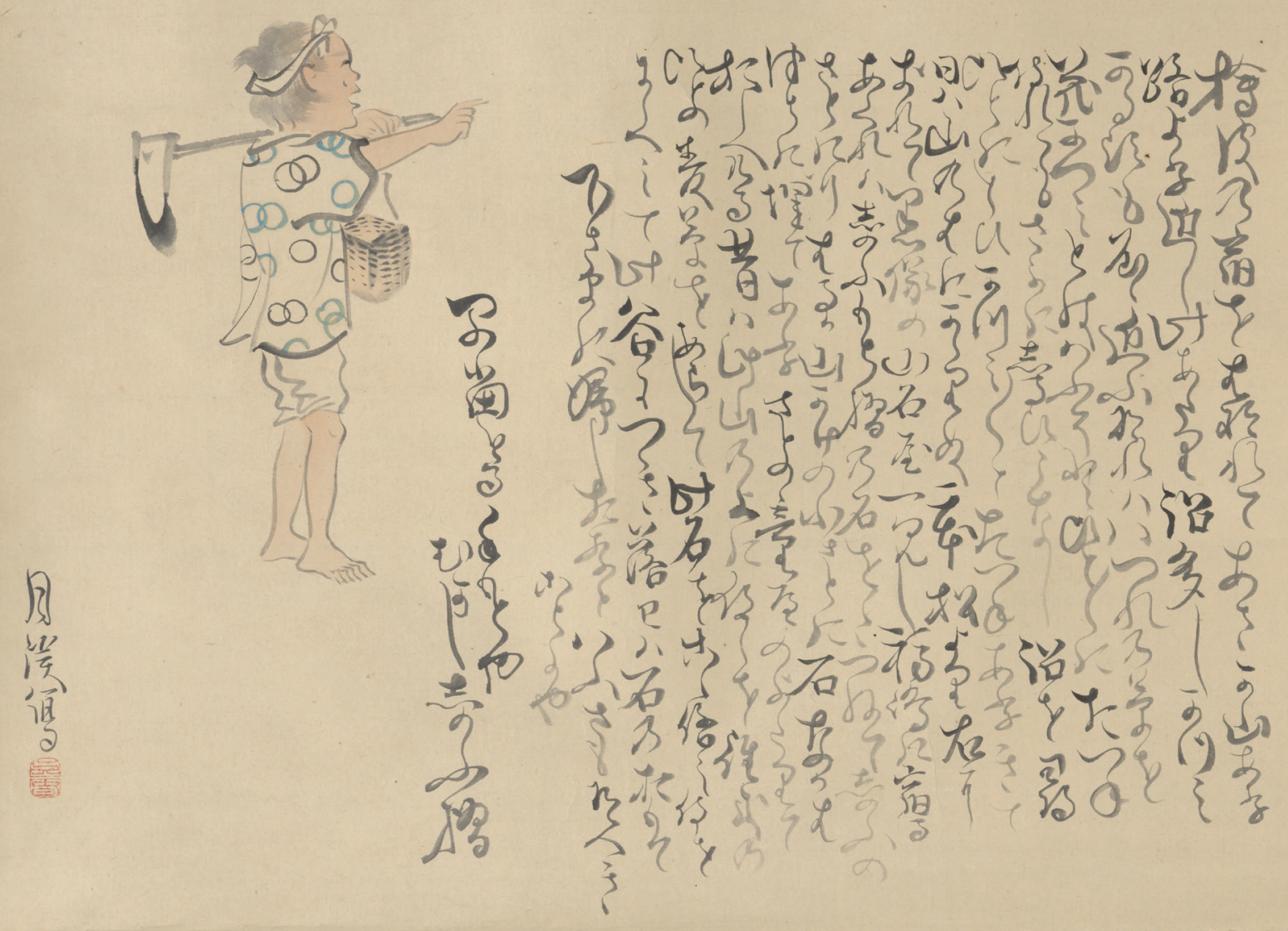




\section{Cat. 2 Setsubun}

Tani Bunchō (1763-1840), hangrolschildering, inkt en kleur op papier, signatuur: 'Bunchō hitsu' ('geschilderd door Bunchō'), zegel: 'Gagaku-sai', Japan, begin 19e eeuw, Rijksmuseum, Amsterdam, inv.nr. AK-RAK-2015-2-3.

Schenking van de heer Filedt Kok, Amsterdam, 2015.

Setsubun is onderdeel van de viering van het Nieuwjaar en men strooit dan bonen, als symbool van reiniging en het verdrijven van kwade geesten. Bunchō laat de bonen strooien door de duivelverjager Shoki, die dat normaal met zijn zwaard en knots doet. De montering haakt aan bij het seizoenthema met een omlijsting van bladzijden van een almanak uit I829.

In zijn jeugd oefende Tani Bunchō zich in figuurstudies door beroemde voorbeelden te kopiëren. ${ }^{3}$ Het resultaat toont zich hier in de grote trefzekerheid. Het is niet meer dan een schets, waarin de figuren volume hebben gekregen met enkele accenten in grijs en roze, maar de virtuositeit van Bunchō's penseel komt er eens te meer in tot uitdrukking. 

Cat. 3 Tsurumeso bij het Gion-festival

Nakajima Kahō (1866-1939), hangrolschildering, inkt en kleur op papier, signatuur: 'Taishō hinoe-tora shoka Kahō sha' ('vervaardigd door Kahō in de vroege zomer van 1926'), zegel: 'Kenshō', Japan, 1926, Rijksmuseum, Amsterdam, inv.nr. AK-RAK-2015-2-6.

Schenking van de heer Filedt Kok, Amsterdam, 2015.

Tsurumeso of tsurusashi waren handwerkslieden die in Kyoto zorgden voor de vervaardiging van sandalen en pezen voor bogen, die beide werden gemaakt van hennepvezels. Ze waren verbonden aan het Gionheiligdom (het huidige Yasaka-heiligdom) en bij het grote Gion-festival in de zomer gingen ze voor de parade uit om de weg te zuiveren. ${ }^{4}$ De drie mannen op deze schildering dragen maskers en de twee wapens (mon) van de tempel zijn te zien op hun borst en de banier die ze op hun rug dragen.

Nakajima Kahō liet zich tegen 1920 inspireren door onder andere Matsumura Goshun, van wie de figuurschildering (cat. I) zich met dit werk laat vergelijken. Het papier van de omlijsting is hier en daar met touw afgebonden voordat het blauw werd geverfd, zodat er een versiering met ronde witte plekken is achtergebleven waar het omwonden deel ongeverfd is gebleven. De montering erboven en -onder is in met parelmoer bedekt papier, dat opzettelijk is gekreukeld om een rustiek effect te krijgen. 
Cat. 4 Benkei

Migita Toshihide (1863-1925), hangrolschildering, inkt en kleur op papier, signatuur: 'Toshihide hitsu' ('geschilderd door Toshihide'), zegel: 'Gosai no in' ('zegel van Gosai'), Japan, eind $19^{\mathrm{e}}$-begin $20^{\mathrm{e}}$ eeuw, Rijksmuseum, Amsterdam, inv.nr. AK-MAK-1713.

Bruikleen van de Vereniging van Vrienden der Aziatische Kunst.

De krijger-monnik Benkei was de trouwe metgezel van de beroemde zwaardkunstenaar Minamoto no Yoshitsune (II59-II89). Hier is hij afgebeeld wanneer hij samen met Yoshitsune vluchtend op een controlepost stuit. Hij doet voorkomen alsof ze geld inzamelen voor een tempel. Op de vraag van de wacht naar een lijst van donors trekt hij zelfverzekerd een lege rol tevoorschijn en begint met stentorstem te declameren.

Het verhaal van loyaliteit en bravoure is vele malen in theatervorm verschenen en Toshihide heeft Benkei hier geportretteerd als de krachtige, gewiekste figuur, zoals hij ook steevast op het toneel wordt gezet. 


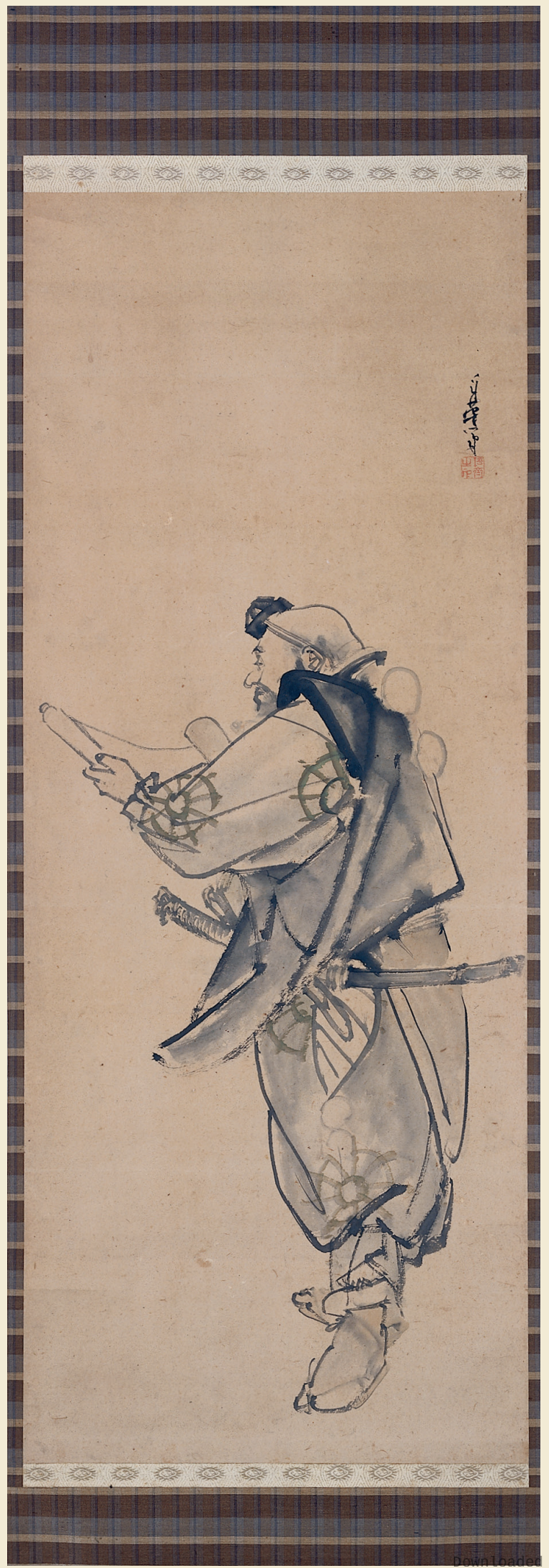


Cat. 5 Langoustines

Mori Sosen (1747-821), hangrolschildering, inkt en kleur op papier, signatuur: 'Sosen', zegel: 'Sosen', Japan, begin $19^{\mathrm{e}}$ eeuw,

Rijksmuseum, Amsterdam, inv.nr. AK-MAK-1711.

Bruikleen van de Vereniging van Vrienden der Aziatische Kunst.

Sosen is in eerste instantie beroemd om zijn schilderingen van apen. Het werken naar de natuur stond voorop en Sosen bracht veel tijd buiten door om de dieren in hun natuurlijke omgeving te observeren en te schetsen. Hij slaagde erin om dieren raak te treffen, niet alleen het uiterlijk maar ook het karakter. Dat vermogen is ook hier zichtbaar. De langoustines zijn met virtuoze inktstreken in talrijke grijze en zwarte tonen neergezet, die goed de glans en structuur van de schaaldelen oproepen.

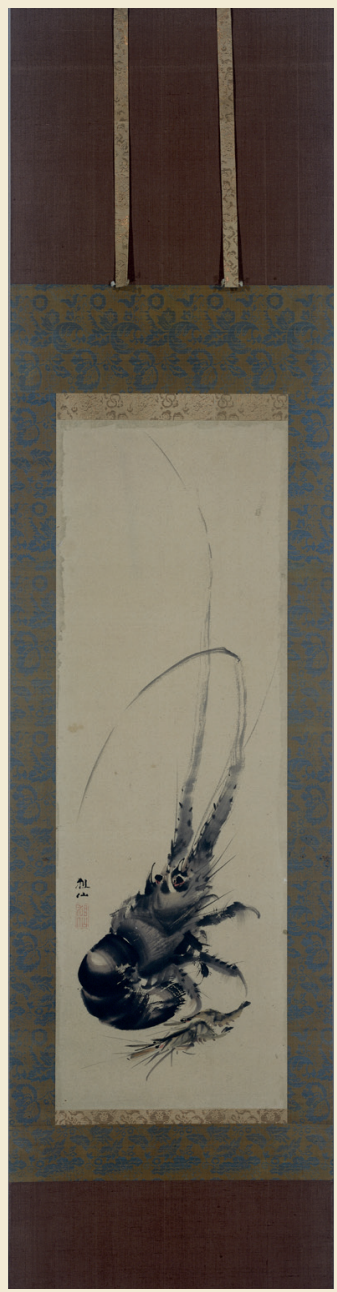


Cat. 6

\author{
Beer en krab \\ Mori Ippō (1798-1871), hangrolschildering, inkt en kleur op \\ papier, signatuur: 'Ippō', zegel: ‘Keishi', Japan, midden $19^{\mathrm{e}}$ eeuw, \\ Rijksmuseum, Amsterdam, inv.nr. AK-RAK-2015-2-2. \\ Schenking van de heer Filedt Kok, Amsterdam, 2015.
}

Mori Ippō toont zijn verwantschap met Mori Sosen (cat. 5) in zijn grote vermogen om dieren te typeren en hun essentie in inkt uit te drukken. Ippō speelt met het verschil in schaal tussen de dieren en balanceert de compositie met de lichte rots en de donkere beer, terwijl de interactie tussen de krab en de beer voor een humoristische noot zorgt. Dit soort visueel aantrekkelijke schilderingen sprak de markt voor schilderkunst aan in de grote stad, waar een ontwikkelde clientèle was die waardering had voor conceptueel en visueel vindingrijke kunstwerken.

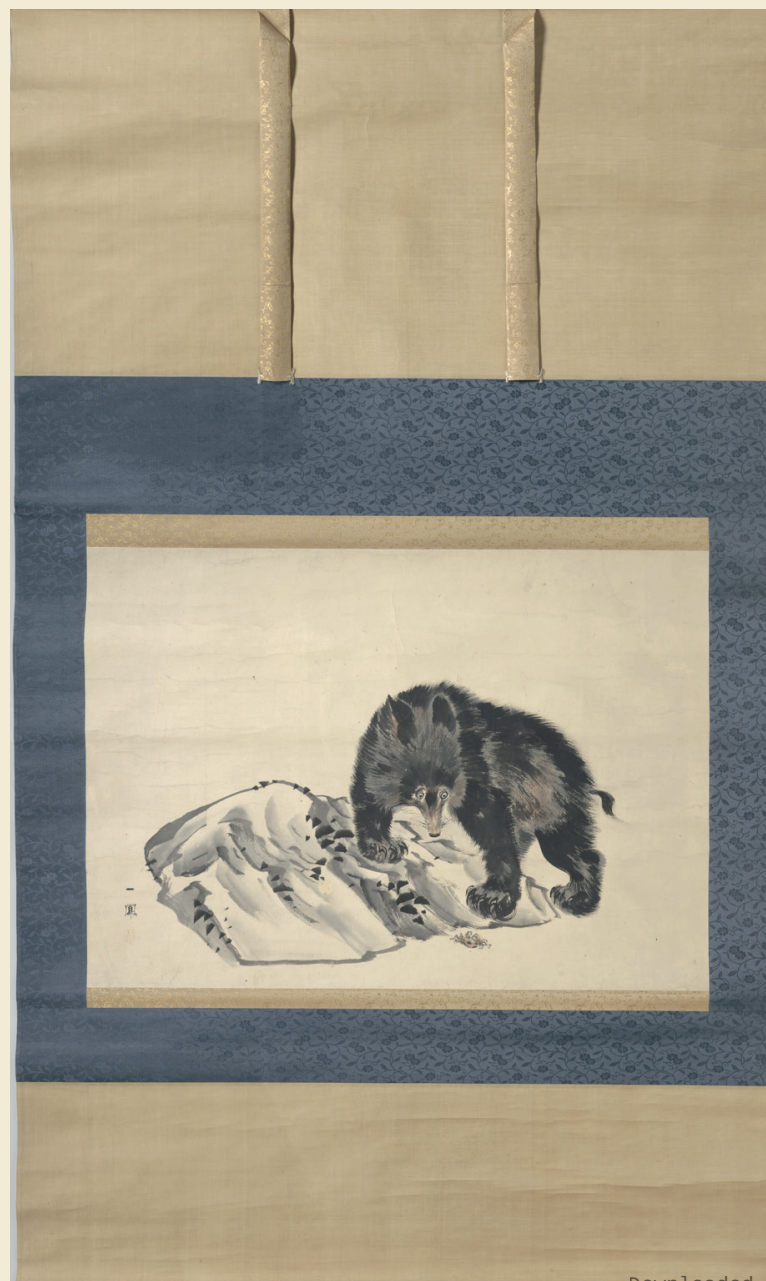




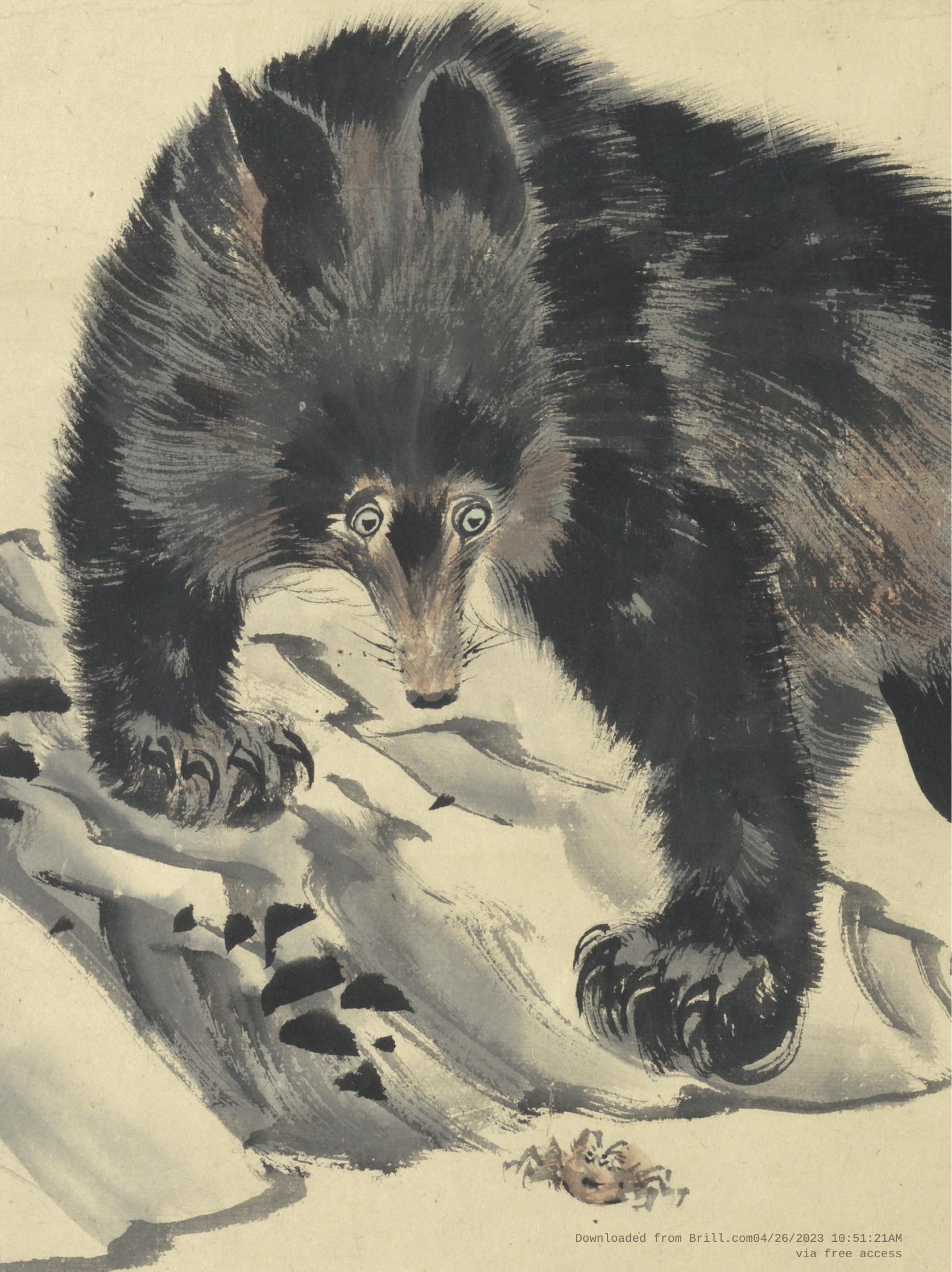


Cat. 7 Tijger

Kōno Bairei (1844-1895), hangrolschildering, inkt en kleur op papier, signatuur: 'Hinoe-tora mōshun shibitsuken Kō Bairei', zegel: 'Kōno Naotoyo', Japan, 1866, Rijksmuseum, Amsterdam, inv.nr. AK-RAK-2015-2-5.

Schenking van de heer Filedt Kok, Amsterdam, 2015.

De cyclische datering geeft aan dat dit een vroeg werk van Bairei moet zijn, geschilderd toen hij als 2I- of 22-jarige in Kyoto in opleiding was. Hij toont zich een competente leerling. Met zorgvuldige, beheerste lijnen heeft hij de tijger vormgegeven, die tot een wat humoristische figuur is geworden, zoals wel vaker het geval is in de Japanse schilderkunst.

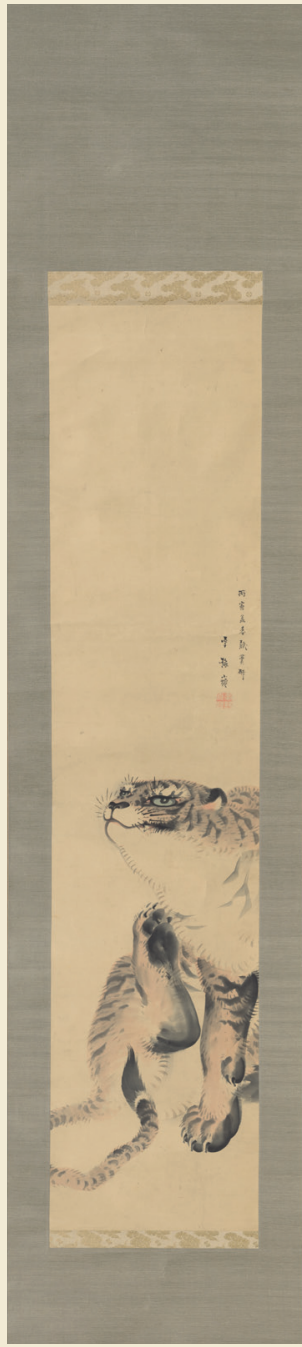




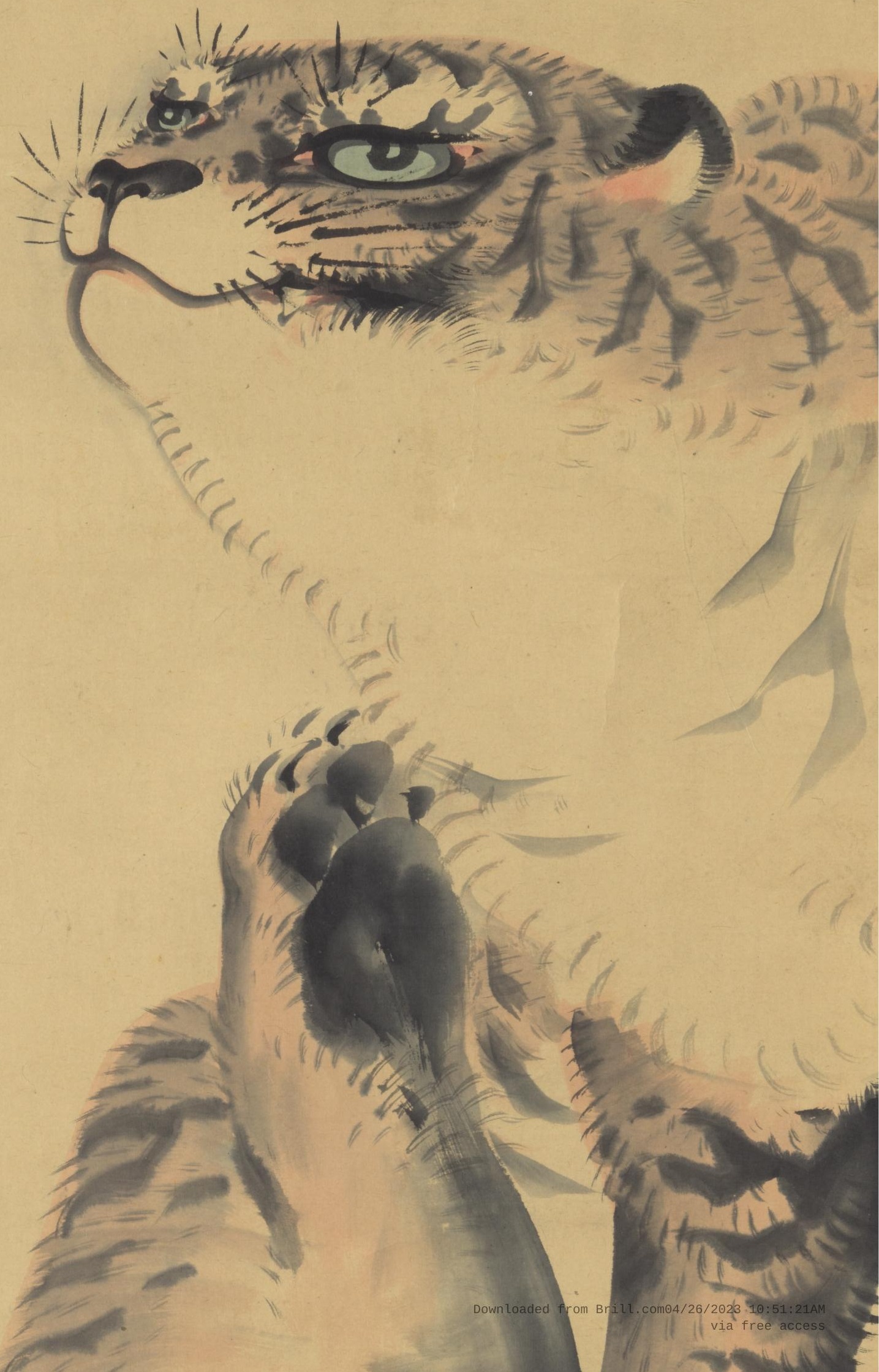


Cat. 8 Lotuswortel en rat

Shibata Zeshin (1807-1891), hangrolschildering, inkt en kleur op papier, signatuur: 'Zeshin sha' ('vervaardigd door Zeshin'), zegel: 'Tairyūkyo', Japan, tweede helft $19^{\mathrm{e}}$ eeuw, Rijksmuseum, Amsterdam, inv.nr. AK-RAK-2015-2-1.

Schenking van de heer Filedt Kok, Amsterdam, 2015.

Shibata Zeshin was een van de meest invloedrijke kunstenaars van de I $9^{\mathrm{e}}$ eeuw. Hij was succesvol als lakwerker, prentontwerper, maar ook als schilder. Zijn vaardigheid in het maken van een origineel ontwerp laat zich zien in de geraffineerde eenvoud van deze gebalanceerde compositie, met de kleine gestalte van de rat op de grote lotuswortel. De vacht van het dier is met subtiel penseelwerk weergeven, net als de subtiele kleuren en textuur van de lotuswortel, aangebracht terwijl het papier nog nat was.

Gewoonlijk wordt de rat samen afgebeeld met een Japanse radijs (daikon). Het kan zijn dat deze schildering een verwijzing is naar de geluksgod Daikoku (zie cat. 9), die in een van zijn verschijningsvormen op een lotus staat.

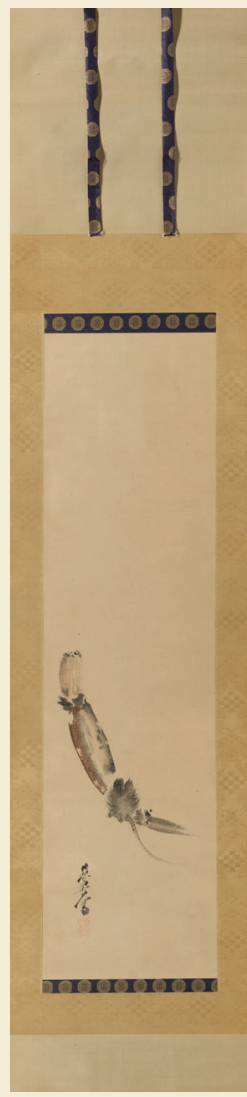


Cat. 9 Rat op de hamer van Daikoku

Takeuchi Seihō (1864-1942), hangrolschildering, inkt en kleur op papier, signatuur: 'Seihō', zegel: 'Seihō gain', Japan, begin $20^{\mathrm{e}}$ eeuw, Rijksmuseum, Amsterdam, inv.nr. AK-RAK-2015-2-7.

Schenking van de heer Filedt Kok, Amsterdam, 2015.

De rat is de vaste metgezel van de god van de rijkdom Daikoku. Hij wordt vaak afgebeeld met een ander attribuut van de geluksgod, de magische houten hamer waarmee Daikoku wensen werkelijkheid kan laten worden.

Takeuchi Seihō heeft de combinatie weergegeven met een prettig contrast tussen de volle, diepzwarte penseelstreken van de hamer en de zachte grijstinten voor de rat. Seihō maakte een groot aantal dierstudies en dit soort makkelijk toegankelijke, vaardig geschilderde werken waren bij een groot publiek geliefd. 


$$
\text { Q. }
$$


Cat. 10 Slak

Suzuki Shōnen (1849-1918), hangrolschildering, inkt en kleur op papier, signatuur: 'Hyakusen', zegel: 'ichinichi sekiga, senmai no ichi', Japan, eind $19^{\mathrm{e}}$ eeuw, Rijksmuseum, Amsterdam, inv.nr. AK-RAK-2015-2-10. Schenking van de heer Filedt Kok, Amsterdam, 2015.

Suzuki Shōnen heeft met een energiek penseel de slak tot een beeldvullende reus uitvergroot. De bravoure spreekt ook uit de enorme signatuur, nog eens benadrukt door de zegel: 'één vel uit duizend, geschilderd op één dag'. Shōnen zou die tour de force op zijn conto hebben geschreven als jonge man en het is aantrekkelijk om te denken dat deze slak inderdaad een van die serie is geweest.

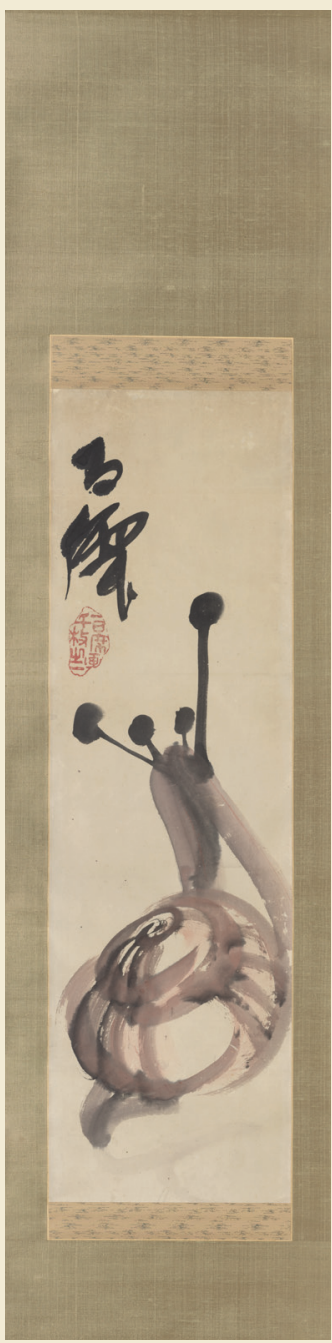




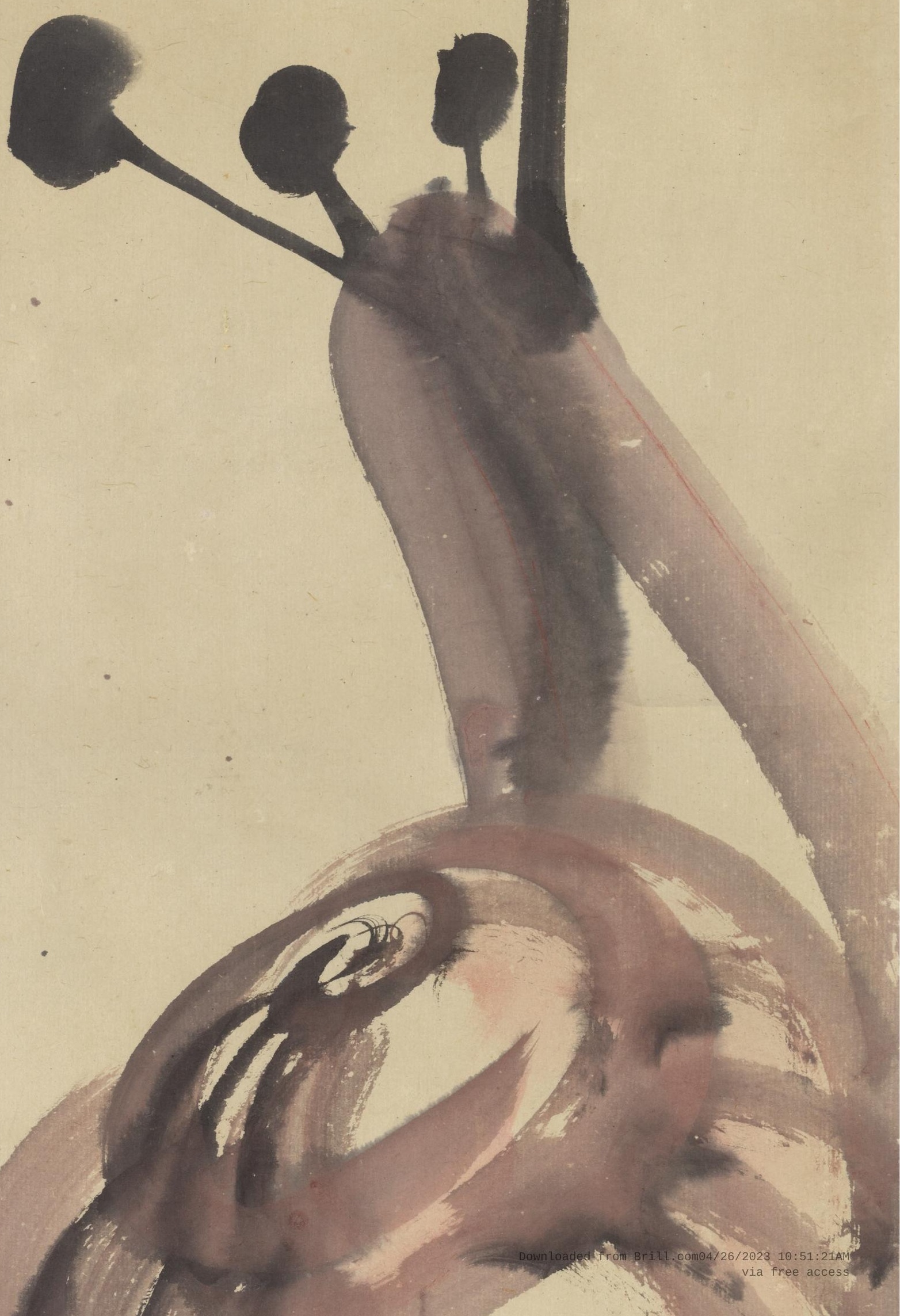


Cat. I I Kalebas met zegels

Rai Sanyō (1780-1832), hangrolschildering, inkt en kleur op papier, Japan, begin $19^{\mathrm{e}}$ eeuw?, Rijksmuseum, Amsterdam, inv.nr. AK-RAK-2015-2-9.

Schenking van de heer Filedt Kok, Amsterdam, 2015.

Rai Sanyo was een Confucianistische geleerde, dichter en schrijver, die ook als kalligraaf te boek staat. Hij had een grote verzameling zegels. Afdrukken van zijn tientallen zegels zijn verzameld in boek- en handrolvorm en hier vullen 57 exemplaren als het ware een hangende kalebas. Het is mogelijk dat Sanyo ook de schildering heeft gemaakt, maar het valt niet uit te sluiten dat zowel de afdrukken als de schildering later zijn gemaakt. ${ }^{5}$

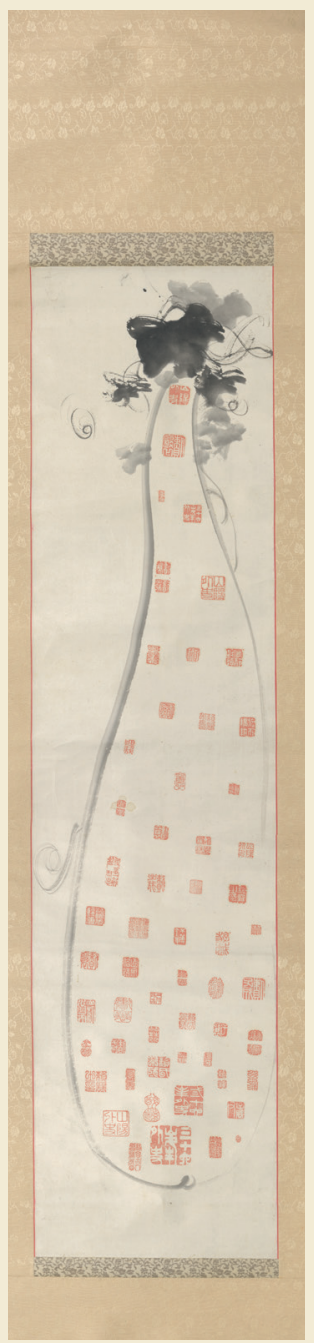


Cat. I2 Vogels na sneeuwval in midwinter

Konoshima Ōkoku (1877-1938), hangrolschildering, inkt op

papier, signatuur: 'Ōkoku', zegel: 'Ōkoku', Japan, 1914,

Rijksmuseum, Amsterdam, inv.nr. AK-RAK-2015-2-8.

Schenking van de heer Filedt Kok, Amsterdam, 2015.

De titel van het werk is op de door de schilder gesigneerde houten doos geschreven, samen met de datering van i9I4. De schildering wil het gevoel oproepen van een midwinterlandschap waar de sneeuwval net is gestopt, met het diffuse licht en de gedempte geluiden.

Verstilling en een wat verloren, eenzame stemming zijn kenmerken van Ōkoku's landschapswerken. Die karakteristieken worden wel in verband gebracht met Ōkoku zelf, die in de vroege $20^{\mathrm{e}}$ eeuw geïsoleerd raakte, toen de kunstwereld zijn wat introverte werk ouderwets ging vinden.

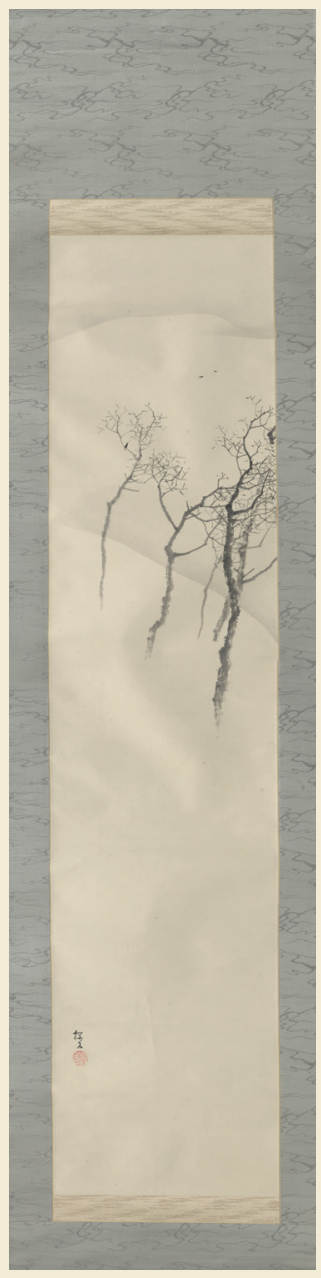


Richard J. Bowring and Peter F. Kornicki, The Cambridge Encyclopedia of Japan, Cambridge University Press, New York, 1993.

F. Chance, 'In the Studio of Painting Study: Transmission Practices of Tani Bunchō', in: Copying the Master and Stealing His Secrets: Talent and Training in Japanese Painting, Honolulu, 2003.

Ellen P. Conant, NIHONGA: Transcending the Past: Japanese-Style Painting, I868-1968, Saint Louis Art Museum, St. Louis, M., I995. [tent.cat.]

Gerald Groemer, Street Performers and Society in Urban Japan, I60o-I90o: The Beggar's Gift, Routledge, Londen \& New York, 2016.

Janice Katz, Japanese Paintings in the Ashmolean Museum, Oxford, Ashmolean Museum, Oxford, 2003.

Michiyo Morioka and Paul Berry, Modern Masters of Kyoto: the Transformation of Japanese Painting Traditions: Nihonga from the Griffith and Patricia Way Collection, Seattle Art Museum/University of Washington Press, Seattle, 1999. [tent.cat.]

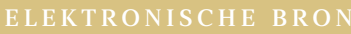

http://www.wul.waseda.ac.jp/kotenseki/html/chiı/chiı_o4606/index.html (laatst bezocht I3 januari 2017)

I Degenen die zich de opstelling Japanse schilderkunst uit bezit van de Vereniging van Vrienden der Aziatische Kunst uit 2000 voor de geest kunnen halen, zullen zich herinneren dat cats. 2, 5, 6 en 8 ook toen al te zien waren.

2 Bowring and Kornicki 1993: 194.

3 Zie, Chance 2003: 63-65.

4 Groemer 2016: 58.

5 Een handrol met 55 zegels in de collectie van de Waseda Universiteit is pas in I915 postuum samengesteld. http://www.wul.waseda.ac.jp/kotenseki/html/chiro/ chiro_04606/index.html (laatst bezocht I3 januari 2017) 